\title{
Irregular flowering patterns in terrestrial orchids: theories vs empirical data
}

\author{
Pavel Kindlmann and Zuzana Balounová
}

Kindlmann, P. and Balounová, Z. 2001. Irregular flowering patterns in terrestrial orchids: theories vs empirical data. - Web Ecol. 2: 75-82.

\begin{abstract}
Empirical data on many species of terrestrial orchids suggest that their between-year flowering pattern is extremely irregular and unpredictable. A long search for the reason has hitherto proved inconclusive. Here we summarise and critically review the hypotheses that were put forward as explanations of this phenomenon: irregular flowering was attributed to costs associated with sexual reproduction, to herbivory, or to the chaotic behaviour of the system represented by difference equations describing growth of the vegetative and reproductive organs. None of these seems to explain fully the events of a transition from flowering one year to sterility or absence the next year. Data on the seasonal growth of leaves and inflorescence of two terrestrial orchid species, Epipactis albensis and Dactylorhiza fuchsii and our previous results are then used here to fill gaps in what has been published until now and to test alternative explanations of the irregular flowering patterns of orchids.
\end{abstract}

P. Kindlmann (pavel@entu.cas.cz), Faculty of Biological Sciences, Univ. of South Bohemia, Branišovská 31, CZ-370 05 České Budějovice, Czech Republic (present address: Ecologie des populations et communautés, Institut National Agronomique Paris-Grignon, 16 Rue Claude Bernard, F-75231 Paris Cedex 05, France). - Z. Balounová, Faculty of Biological Sciences and Faculty of Agriculture, Univ. of South Bohemia, Branišovská 31, CZ-370 05 České Budějovice, Czech Republic.

Marked variations in flowering frequency, and irregular patterns of appearance above ground between years, were observed in many perennial herbs, among them various species of terrestrial orchids, such as Dactylorhiza sambucina (L.), Dactylorhiza incarnata (Druce), Orchis mascula (L.) and Listera ovata (L.) R. Brown (Tamm 1956, 1972), Spiranthes spiralis (L.) Chevallier, Aceras anthropophorum (L.) Sm. and Herminium monorchis (L.) R. Brown (Wells 1981), Ophrys sphegodes Miller (Hutchings 1987), Ophrys apifera Hudson (Wells and Cox 1991), Tipularia discolor (Pursh) Nutt. (Whigham and O’Neill 1991) etc.
However, other data on terrestrial orchids indicate conspicuous regularities in their life histories (Wells and Cox 1989, Leeson et al. 1991). Primack and Hall (1990) demonstrate that a greater investment in reproduction led to increasingly negative effects on the probability of flowering and leaf area in Cypripedium acaule Aiton. In small plants of Catasetum viridiflavum Hook., unlike larger (older) ones, the amount of stored nutrients appears important for both vegetative growth and flowering (Zimmerman 1990). Defoliation has a negative effect on the belowground corms in Tipularia discolor (Whigham 1990). Storage is relatively unimportant for the recovery of $T$. discolor 
from herbivory, but is important in growth initiation and reproduction (Zimmerman and Whigham 1992). Rainfall is positively correlated with the number of flowers and height of inflorescence (Wells and Cox 1991). It is assumed that the irregular patterns in flowering are the result of costs associated with sexual reproduction and leaf herbivory (Whigham and O'Neill 1991).

The transition probabilities from one stage in a particular year to another stage the next year (e.g. flowering one year - dormant the next year etc.) lead to matrix models (Gregg 1991, Waite and Hutchings 1991). Being stochastic, they - by definition - lead to a seemingly "chaotic" behaviour. Can there, however, be predicted anything more than a probability of flowering, being sterile or dormant, if there are other predictable patterns in orchid behaviour?

The now rich life-history literature makes predictions about the optimal energy allocation between vegetative and reproductive growth and storage and should therefore be able to explain this phenomenon. However, under assumptions reasonable for perennial herbs without permanent above-ground structures and with persistent reserve structures, thus including the terrestrial orchids mentioned above, the theoretical predictions of life history are different. Pugliese (1987) predicts that the optimal strategy is to reach a certain equilibrium size of the perennating reserve structure in a finite time and then to maintain this size for the rest of life. As the reproductive effort in year $t$, $\mathrm{E}_{\mathrm{t}}$ (the percentage of available photosynthate allocated to reproduction) is uniquely determined by the size of the reserve structures in years $\mathrm{t}-1$ and $\mathrm{t}$ in his model, $\mathrm{E}_{\mathrm{t}}$ should also remain constant later in the life. Similarly, Pugliese and Kozlowski (1990) predict a critical proportion of persistent organs, below which it is optimal to grow without reproduction until a characteristic size is reached. That size is maintained year after year thereafter and all extra resources are devoted to reproduction. Their numerical simulations suggest that reproduction should also remain constant later in the life. These models assume a constant environment, or a low sensitivity of the plants to changes of the environment.

Iwasa (1991) predicts that a plant adapted to a slowly changing environment should continue to grow until late in a favourable environment, but should start reproduction earlier in an unfavourable one. In a quickly changing environment, a plant should use an almost fixed growth schedule. Thus, in a mixture of different-aged plants, some plants should flower and some should not. Howev$\mathrm{er}$, following the fate of one particular plant through more years would not yield a chaotic flowering regime again, as - within the season - they first grow and then always flower in Iwasa's (1991) model. The problem with orchids and many other plants is that the decision about flowering is made early in the season and after that both vegetative and generative organs grow simultaneously. This simultaneous energy allocation to growth and re- production does have a theoretical explanation: a constraint to the reproductive growth rate (Kozlowski and Ziolko 1988, Kindlmann and Dixon 1989, Kindlmann and Balounová 1999b).

Loehle (1987) predicted that the plant should allocate its energy to either vegetative or sexual reproduction according to detectable changes in the environmental conditions. If the plants experience different conditions early in the season from year to year, then this, together with differences in their reserve size at this time, might lead to seemingly "chaotic decisions" about flowering.

Inghe (1990) tried to explain irregular flowering patterns by means of computer simulations of difference equations. Assuming a deterministic (exponential or logistic) growth of the vegetative dry weight and a deterministic relationship between vegetative and reproductive dry weight, he concluded that the irregular flowering patterns within one plant might be partly explained by the chaotic behaviour of the corresponding difference equations. If this is true, then the year-to-year relation of plant sizes can be deterministic: the plant size the next year can be predicted from its size in the previous year.

In the recent years we tested some of the above hypotheses (Kindlmann 1999, Kindlmann and Balounová 1999a). Here we aim to add some yet unpublished results, to summarise what was achieved by ourselves and others and to formulate a state-of-the art answer to the question of what are the causes of the irregular flowering patterns in terrestrial orchids.

\section{Empirical data}

We used two data sets. One was published by Rydlo (1995). He studied a population of Epipactis albensis on a permanent $23 \times 65 \mathrm{~m}$ plot in the Libický luh floodplain forest (the Labe lowland, central Bohemia) in 1979-1993. During this period, he marked altogether 833 individuals growing along a row of poplars (Populus $\times$ canadensis) with a vinyl tube $20 \mathrm{~cm}$ from the plant and monitored the shoot length and the number of flowers. Only those plants which appeared above ground at least twice during the experimental period (238 individuals in total) were included in this analysis. We assumed the "age" of plants to be 1 at the year of their first appearance, although they may have lived below ground for several years before.

As Rydlo's data - similarly to most other ones - only included information about mode of performance (dormancy, sterility or flowering) and no measurements were done of actual sizes of the plants and their parts, we collected another data set in the site Ohrazeni II containing a large population of $D$. fuchsii. Maximum width and length of each leaf, length of shoot, number of flowers and from 1995 also number of capsules of all $D$. fuchsii plants (99-142, depending on the year) were recorded at each site at approximately weekly intervals during the whole 
vegetative season in 1994 and 1995 and once at the peak flowering seasons in 1996 and in 1997.

In the site Ohrazeni II the orchids were originally spread in a meadow and extended to a forest path. The site, however, was abandoned and not maintained. Half of the original meadow was mown once ten years ago; the other one was left untouched. Ohrazeni II now consists in principle of three different sites. We refer to them as: 1) meadow - willow and birch seedlings appear, old grass present, 2) shrubs - a more advanced and quickly proceeding successional stage, 2-3 $\mathrm{m}$ high willow and birch thickets now shading the site almost completely, and 3) forest - the original forest path, remaining almost unchanged, some but not much old grass present.

Total leaf area was estimated by summing $\mathrm{q}$ (width $\times$ length) for all leaves of a plant. Within a species, the leaves are geometrically similar and therefore $\mathrm{q}$ is a constant and was in this case set equal to 0.5 . Although this may not be the true value of $\mathrm{q}$, it did not affect the subsequent analyses, in which the relative total leaf areas of plants are compared.

These two data sets have already been subjected to various analyses (Kindlmann 1999, Kindlmann and Balounová 1999a, b). Here we use only the unpublished ones and refer to original sources for the rest.

\section{Results and discussion}

\section{Possible artefacts of data collection}

In Kindlmann and Balounová (1999a) we were concerned that the estimate of transitions, based on a single observation in the peak season, might be biased. For example, a plant that initiated an inflorescence might be grazed completely before being observed and thus be considered as absent. As we have shown in Kindlmann and Balounová (1999a), there is almost no difference between the results for one and for multiple observations per year. Thus, at least in our case, for observations of transitions between individual life stages one observation per year is sufficient.

\section{Inghe's hypothesis}

It was already shown elsewhere (Kindlmann 1999) that the irregular flowering pattern in Epipactis albensis cannot be explained by Inghe's (1990) hypothesis. Here we bring one additional argument.

In Rydlo's (1995) data, the shoot length was positively correlated with the number of flowers for plants of the same age (Table 1). The slope of the dependence of the number of flowers on shoot length for plants of the same age declines in old age (Table 1). Larger plants therefore invest proportionally less into flowers, if they are old. The $\mathrm{x}$-intercept of this relationship, which in biological terms is the average minimum critical shoot length for flowering, does exist and is independent of age.

In Fig. 1 Rydlo's (1995) data on E. albensis are used, the co-ordinates are shoot length and number of flowers in one ("predicting") year and the type of the dot indicates the behaviour of this plant the next ("estimated") year: dormancy, sterility or flowering. Only those couples of years in which all three types of behaviour in the "estimated" year were present are depicted. Within the "predicting" year, the sterile plants (dots on the $\mathrm{x}$-axis) are consistently small. However, regularity is completely lacking in the flowering pattern in the "estimated" year as a function of the plant performance in the previous year.

A very similar situation is shown in Fig. 2 for D. fuchsii. Leaf areas in two subsequent years are positively and linearly correlated, but there is no difference between flowering and sterile plants in this respect.

In summary, shoot length in sterile plants is always small, as compared to plants flowering the same year and follows the data given in Table 1, but sterility or dormancy cannot be predicted from shoot length and number of flowers in the preceding year. This is an additional argument against the Inghe's (1990) hypothesis.

Table 1. Linear regressions and correlation coefficients between shoot length (independent variable) and number of flowers for plants of the same age ( $\mathrm{n}$ is the number of individuals). Data on Epipactis albensis from 1979 to 1993 collected by Rydlo (1995).

\begin{tabular}{|c|c|c|c|c|c|c|}
\hline age & slope & $y$-intercept & $\mathrm{x}$-intercept & $\mathrm{r}$ & $\mathrm{n}$ & $\mathrm{p}$ \\
\hline 1 & 0.32 & -1.77 & 5.46 & 0.84 & 238 & $<0.001$ \\
\hline 3 & 0.33 & -1.96 & 5.93 & 0.90 & 97 & $<0.001$ \\
\hline 4 & 0.31 & -1.20 & 3.93 & 0.78 & 46 & $<0.001$ \\
\hline 5 & 0.36 & -1.80 & 4.99 & 0.84 & 40 & $<0.001$ \\
\hline 7 & 0.20 & -1.21 & 6.02 & 0.82 & 13 & $<0.001$ \\
\hline 8 & 0.23 & -1.05 & 4.49 & 0.89 & 5 & $<0.05$ \\
\hline average & 0.30 & -1.58 & 5.33 & & & \\
\hline
\end{tabular}


(a)

1979-1980

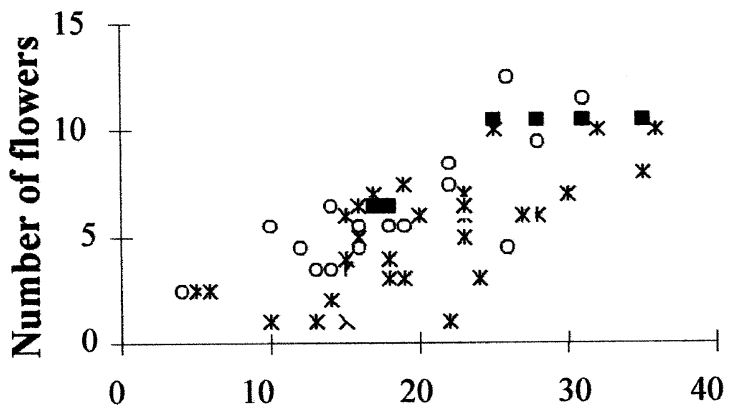

Shoot length (cm)

(c)

1981-1982

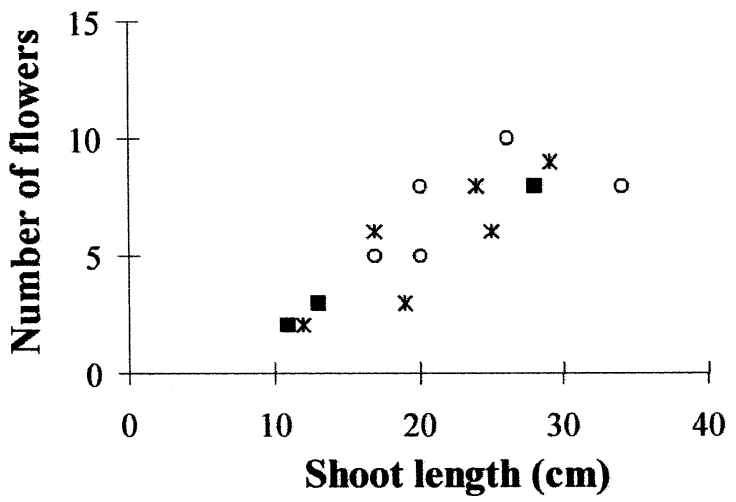

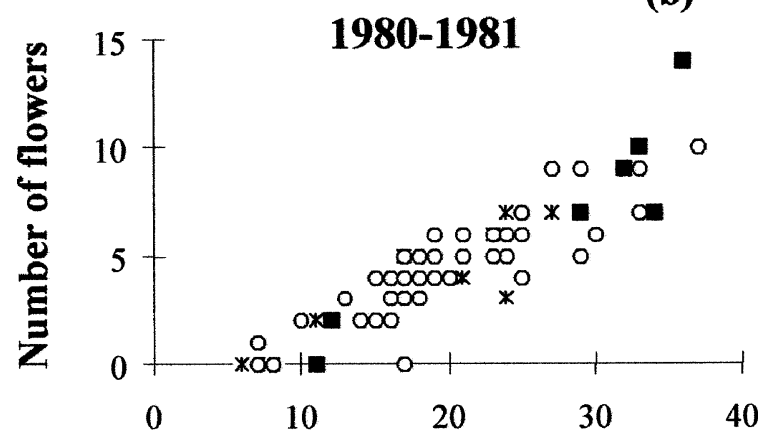

(d)

1984-1985

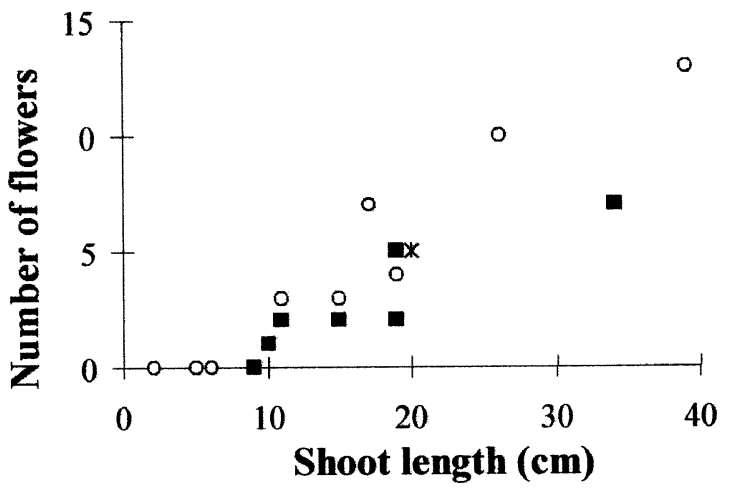

Fig. 1. Shoot length in $\mathrm{cm}$ and number of flowers in all Epipactis albensis plants that first appeared in 1979 (a), 1980 (b), 1981 (c) and 1984 (d), with indication of their performance in the subsequent year. $\mathrm{x}$ : flowering, $\mathbf{\square}$ : sterile, $\bigcirc$ : dormant.

\section{Stochasticity of the environment}

The decision on whether the plant will flower, be sterile or remain dormant, is made early in the season or late in the preceding season (Leeson et al. 1991). Reserve size is one factor in this decision and microhabitat environmental conditions at this time are probably the other. The latter assumption cannot be applied to global environmental conditions, as it would lead to the same strategy in different plants with the same history and this is not supported by empirical data. There is no reason for not believing that evolution shaped the plant strategies in the direction of optimisation of their energy budget. Therefore, optimum energy-partitioning models should be able to explain the irregular flowering pattern, provided variability in environment is among their assumptions, as in Iwasa (1991).

It is well known and strongly supported by Tamm (1972) and others that there are certain "orchid years" in which most of them flower, while in other years, almost no plants flower. Our unpublished observations indicate that the "orchid years" may be species specific. Wells et al. (1998) have shown that weather is a major factor causing whole populations not to flower.

\section{Grazing}

Whigham (1990) has reported a negative effect of defoliation on the belowground corms. Kindlmann and Balounová (1999a), however, claim that in most cases grazing does not seem to account for the "not explained" cases in populations of Dactylorhiza majalis. In this paper we bring additional data on $D$. fuchsii, in which grazing also does not seem to account for the "not explained" cases. In Table 2 the numbers of flowering plants $(\mathrm{F})$ of sterile plants $(S)$, their total $(T=F+S)$ and number of grazed 

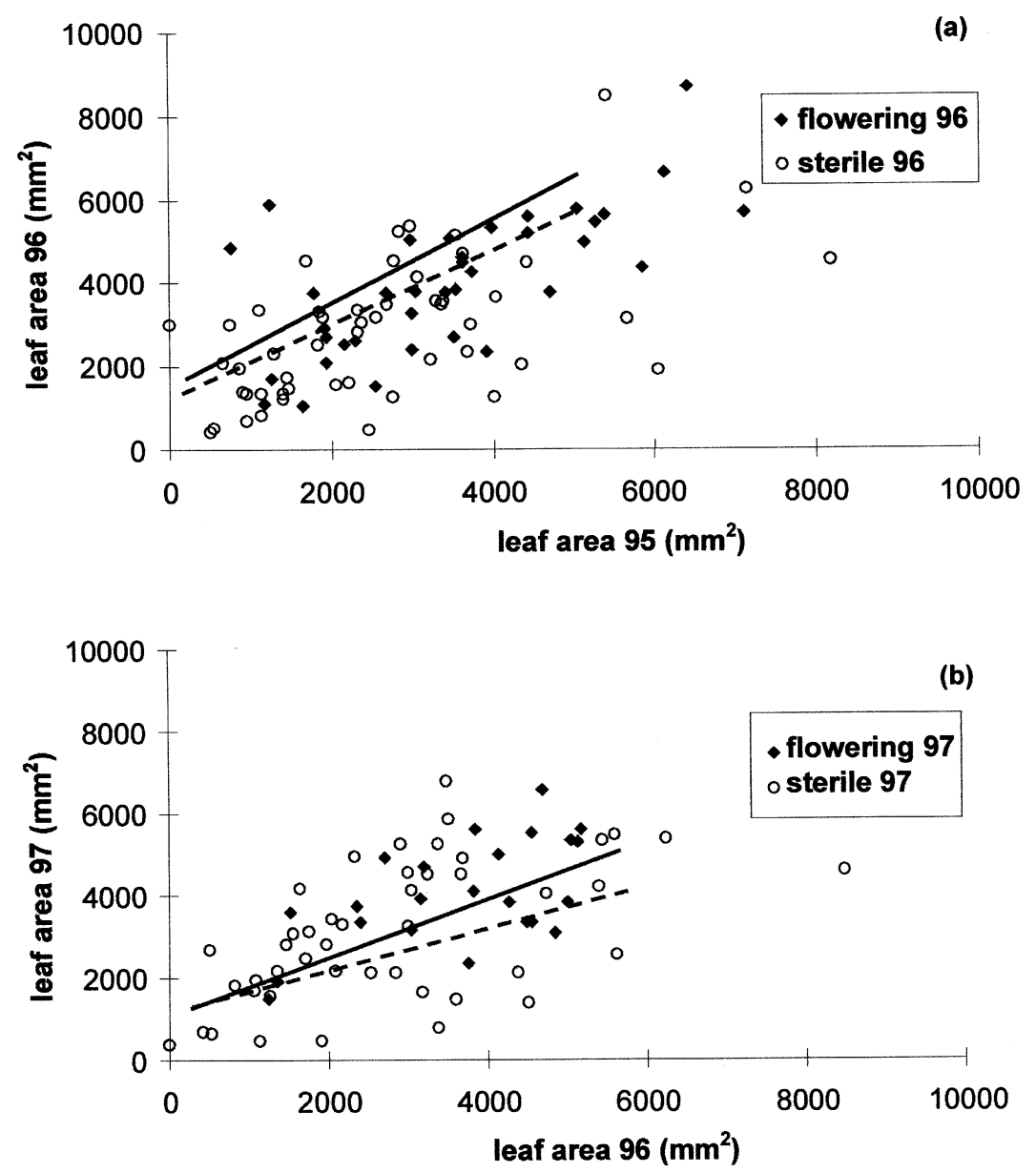

Fig. 2. Correlation between leaf area in $\mathrm{mm}^{2}$ of Dactylorhiza fuchsii in two consecutive years 1995 vs 1996 (a) and 1996 vs 1997 (b). : flowering the next year, $\bigcirc$ : sterile the next year.

plants $(G)$ are shown. Some additional values are calculated: percentages of flowering plants $(\% \mathrm{~F})$, percentages of grazed plants $(\% \mathrm{G})$ and numbers of transitions between flowering one year and sterile the next year (FS). Percentages of the FS plants out of all plants which flowered the previous year $(\% \mathrm{FS})$ and percentages of grazed plants in all FS plants (FSG) are then used to calculate the percentage of "not explained" plants. The percentages of "not explained" plants, i.e., those which flowered and were not grazed one year, but were sterile the next year, are consistently very large. Incidence of grazing among the FS plants (those which behaved irregularly) was not higher than that among all plants. Thus by means of our data on $D$. fuchsii we are not able to reject the null hypothesis that grazing does not contribute significantly to irregular flowering patterns, which is in contrast with Whigham (1990).

This discrepancy may be explained as follows: defoliation, which imitates insect feeding, leaf diseases etc., lowers assimilation and therefore the size of overwintering storage organs (next year tuber or pseudobulb), which may then become of subcritical size and cause sterility the next year.
Grazing by large mammals like deer - as in our case, however, is not selective and in most cases both leaves and inflorescence are grazed. Thus, although in this case assimilation is lowered, too, the plant "saves" energy by not spending it on costly reproduction and in many cases the resulting storage size is not affected. It would be nice to test this hypothesis experimentally.

The effect of grazing on orchid populations also probably depends on its timing and intensity. Wells (pers. comm.) reports that grazing by large mammals (e.g. sheep, cattle) can have a devastating effect on orchid populations and can have a major effect on flowering. Grazing by rabbits both destroys the habitat and also results in severe defoliation of certain species (Wells pers. comm.). On the other hand, a good sheep grazing management can maintain thriving orchid populations for years and cause them to significantly increase in numbers, as is the case of the populations in South Limburg (Willems 1989, Willems and Lahtinen 1997). Therefore, the effect of grazing is ambiguous and would deserve further studies. 
Table 2. Number of flowering plants $(F)$, of sterile plants $(S)$ and their total $(T=F+S)$, number of grazed plants $(G)$, percentage of flowering and grazed plants, $(\% \mathrm{~F})$ and $(\% \mathrm{G})$, respectively, number of transitions flowering in two consecutive years (FF) and flowering one year - sterile the next year (FS), number of FS plants which were grazed (FSG), percentage of the FS plants out of all plants which flowered the previous year $\% \mathrm{FS}=100^{*} \mathrm{FS} /(\mathrm{FF}+\mathrm{FS})$ and percentage of FSG plants in all FS plants ("not explained" $-\% \mathrm{NE}=100^{*}(1-$ FSG/FS)). Data on Dactylorhiza fuchsii from 1994-1997.

\begin{tabular}{llrrrrrrrrrrr}
\hline Year & & $\mathrm{F}$ & $\mathrm{S}$ & $\mathrm{G}$ & $\mathrm{T}$ & $\% \mathrm{~F}$ & $\% \mathrm{G}$ & $\mathrm{FF}$ & $\mathrm{FS}$ & $\mathrm{FSG}$ & $\% \mathrm{FS}$ & $\%$ NE \\
\hline \multirow{2}{*}{1994} & Meadow & 37 & 17 & 19 & 54 & 69 & 35 & 19 & 4 & 1 & 17 & 75 \\
& Forest & 20 & 36 & 50 & 56 & 36 & 89 & 5 & 12 & 11 & 71 & 8 \\
& Shrubs & 20 & 12 & 28 & 32 & 63 & 88 & 10 & 8 & 5 & 44 & 38 \\
& Total & 77 & 65 & 97 & 142 & 54 & 68 & 34 & 24 & 17 & 41 & 29 \\
1995 & Meadow & 27 & 8 & 24 & 35 & 77 & 69 & 19 & 3 & 1 & 14 & 67 \\
& Forest & 10 & 44 & 34 & 54 & 19 & 63 & 2 & 7 & 3 & 78 & 57 \\
& Shrubs & 14 & 15 & 24 & 29 & 48 & 83 & 2 & 4 & 4 & 67 & 0 \\
& Total & 51 & 67 & 82 & 118 & 43 & 69 & 23 & 14 & 8 & 38 & 43 \\
1996 & Meadow & 21 & 13 & 13 & 34 & 62 & 38 & 11 & 0 & 0 & 0 & \\
& Forest & 11 & 37 & 26 & 48 & 23 & 54 & 5 & 5 & 4 & 50 & 20 \\
& Shrubs & 8 & 9 & 5 & 17 & 47 & 29 & 0 & 6 & 1 & 100 & 83 \\
& Total & 40 & 59 & 44 & 99 & 40 & 44 & 16 & 11 & 5 & 41 & 55 \\
& Meadow & 24 & 2 & 26 & 26 & 92 & 100 & & & & & \\
& Forest & 11 & 35 & 26 & 46 & 24 & 57 & & & & &
\end{tabular}

\section{Cost of reproduction}

The negative effect of a large investment into reproduction that leads to sterility or dormancy the next year has been reported by Whigham and O’Neill (1991). However, there might be a difference with respect to this between deceptive orchid species (species which do not produce any nectar, therefore "deceive" the pollinators and rely on naive ones, which pollinate them by mistake) and rewarding ones (nectar producing, offering reward to pollinators) for the following reason.

The reproductive success (RS) of rewarding species is mostly close to $100 \%$, thus - more importantly - variation in RS is low. Thus evolution might have adjusted the dependence of the number of flowers produced on storage size. As a consequence, storage size is not significantly affected by the small variation in RS and once attained the above-critical size for flowering, this size will be kept for years.

In deceptive species, on the other hand, variation in RS is extreme (Jersáková and Kindlmann 1998) and therefore evolution had to adjust the dependence of the number of flowers produced on storage size with respect to the expectation of some average RS. Thus the size of overwintering storage organs strongly depends on RS in the preceding season, which - because of deceptivity - varies dramatically. In plants which happened to have an above-average RS in some season it may often happen that storage which was of above-critical size the previous year becomes sub-critical the next year.

\section{Habitat deterioration}

Kindlmann and Balounová (1999a) suggested, based on data on D. majalis, that the observed irregular flowering regimes should be typical for sites with declining populations - either because of unsuitable habitat, deteriorating management or for unsuitable weather conditions in a particular year.

This is further supported by Table 2 here. The worst habitat in the site Ohrazeni II was the shrubs, which during the years of the study formed a non-penetrable thicket. This caused a strong decline of the population here, accompanied by low incidence of flowering and typically to the FS (flower one year, be sterile the next year) behaviour or death of the plant. This changed after parts of the shrubs were cleared in 1997, after which many small sterile plants appeared.

In the meadow the population was also steadily decreasing due to absence of mowing. The proportion of "not explained" plants (\%NE) was very large in two years and not measurable in the third one (no FS plants in 1996).

In the forest site, where the conditions were the best, the numbers of plants did not decline as dramatically as in other sites. The incidence of both the FS type of behaviour and the percentage of NE plants was the lowest, although the percentage of grazed plants did not differ from that in the other sites.

If correct, the hypothesis that irregular flowering regimes are characteristic for sites with temporarily or steadily declining populations and not usually present in pros- 
perous ones could account for the controversy between predictions of theoretical models and empirical observations, at least in some species. If both climatic and habitat conditions are good, irregular flowering should not be the case, which is in accord with the predictions of life history models. If either of these conditions gets worse, transitions from flowering to sterility or absence may become more frequent and lead eventually to extinction of the population.

\section{Conclusions}

The irregular flowering patterns in terrestrial orchids are neither an artefact of the way the data were collected, nor a result of chaotic behaviour of mathematical equations. The literature reviewed here and the data presented here show that they are caused by a complex of biotic and abiotic factors, which can act in both ways and it depends on the site and species, which one is the most important. These factors include: 1 ) weather; 2 ) grazing by mammals, by insects and underground grazing of storage organs; 3 ) leaf diseases; 4) cost of reproduction in species, in which reproductive success varies substantially; 5) habitat management and 6) habitat deterioration.

Acknowledgements - This research was supported by the grants No. 206/95/1549 and 206/00/1124 of the GA CR and would never have been possible without using the precious data collected by J. Rydlo. We thank T. C. E. Wells for valuable comments.

\section{References}

Gregg, K. B. 1991. Variation in behaviour of four populations of the orchid Cleistes divaricata, an assessment using transition matrix models. - In: Wells, T. C. E. and Willems, J. H. (eds), Population ecology of terrestrial orchids. SPB Acad. Publ. bv, The Hague, pp. 139-159.

Hutchings, M. J. 1987. The population biology of the early spider orchid, Ophrys sphegodes Mill. I. A Demographic study from 1975 to 1984 . - J. Ecol. 75: 711-727.

Inghe, O. 1990. Computer simulations of flowering rhythms in perennials - is there a new area to explore in the quests for chaos? - J. Theor. Biol. 147: 449-469.

Iwasa, Y. 1991. Pessimistic plant: optimal growth schedule in stochastic environments. -Theor. Popul. Biol. 40: 246-268.

Jersáková, J. and Kindlmann, P. 1998. Patterns of pollinator-generated fruit set in Orchis morio (Orchidaceae). - Folia Geobot. 33: 377-390.

Kindlmann, P. 1999. Are orchid life histories really irregular? The case of Epipactis albensis. - Oikos 85: 265-270.

Kindlmann, P. and Dixon, A. F. G. 1989. Developmental constraints in the evolution of reproductive strategies: telescoping of generations in parthenogenetic aphids. - Funct. Ecol. 3: 531-537.

Kindlmann, P. and Balounová, Z. 1999a. Flowering regimes of terrestrial orchids: chaos or regularity? - J. Veg. Sci. 10: 269-273.
Kindlmann, P. and Balounová, Z. 1999b. Energy partitioning in terrestrial orchids - a model for assessing their performance. - Ecol. Modell. 119: 167-176.

Kozlowski, J. and Ziolko, M. 1988. Gradual transition from vegetative to reproductive growth is optimal when the maximum rate of reproductive growth is limited. - Theor. Popul. Biol. 34: 118-129.

Leeson, E., Haynes, C. and Wells, T. C. E. 1991. Studies of the phenology and dry matter allocation of Dactylorhiza fuchsii. - In: Wells, T. C. E. and Willems, J. H. (eds), Population ecology of terrestrial orchids. SPB Acad. Publ. bv, The Hague, pp. 125-138.

Loehle, C. 1987. Partitioning of reproductive effort in clonal plants: a benefit-cost model. -Oikos 49: 199-208.

Primack, R. B. and Hall, P. 1990. Costs of reproduction in the pink lady slipper orchid, a four-year experimental study. Am. Nat. 136: 638-656.

Pugliese, A. 1987. Optimal resource allocation and optimal size in perennial herbs. - J. Theor. Biol. 126: 33-49.

Pugliese, A. and Kozlowski, J. 1990. Optimal patterns of growth and reproduction for perennial plants with persisting or not persisting vegetative parts. - Evol. Ecol. 4: 75-89.

Rydlo, J. 1995. Long-term observation of the Epipactis albensis population on the permanent plot in the Libický luh floodplain forest. - Muzeum a souèasnost, ser. natur. 9: 81-98, in Czech.

Tamm, C. O. 1956. Further observations on the survival and flowering of some perennial herbs. - Oikos 7: 274-292.

Tamm, C. O. 1972. Survival and flowering of some perennial herbs. II. The behaviour of some orchids on permanent plots. - Oikos 23: 23-28.

Waite, S. and Hutchings, M. J. 1991. The effects of different management regimes on the population dynamics of Ophrys sphegodes: analysis and description using matrix models. - In: Wells, T. C. E. and Willems, J. H. (eds), Population ecology of terrestrial orchids. SPB Acad. Publ. bv, The Hague, pp. $161-175$.

Wells, T. C. E. 1981. Population ecology of terrestrial orchids. In: Synge, H. (ed.), The biological aspects of rare plant conservation. Huntingdon, England, pp. 281-295.

Wells, T. C. E. and Cox, R. 1989. Predicting the probability of the bee orchid (Ophrys apifera) flowering or remaining vegetative from the size and number of leaves. - In: Pritchard, $\mathrm{H}$. W. (ed.), Modern methods in orchid conservation: the role of physiology, ecology and management. Cambridge Univ. Press, pp. 127-139.

Wells, T. C. E. and Cox, R. 1991. Demographic and biological studies on Ophrys apifera: some results from a 10 year study. In: Wells, T. C. E. and Willems, J. H. (eds), Population ecology of terrestrial orchids. SPB Acad. Publ. bv, The Hague, pp. 47-61.

Wells, T. C. E. et al. 1998. Flowering dynamics of Orchis morio (L.) and Herminium monorchis (L.) R.Br. at two sites in eastern England. - Bot. J. Linn. Soc. 126: 39-48.

Whigham, D. F. 1990. The effect of experimental defoliation on the growth and reproduction of a woodland orchid, Tipularia discolor. - Can. J. Bot. 68: 1812-1816.

Whigham, D. F. and O'Neill, J. 1991. The dynamics of flowering and fruit production in two eastern North American terrestrial orchids, Tipularia discolor and Liparis lilifolia. - In: Wells, T. C. E. and Willems, J. H. (eds), Population ecology of terrestrial orchids. SPB Acad. Publ. bv, The Hague, pp. 89-101. 
Willems, J. H. 1989. Population dynamics of Spiranthes spiralis in South-Limburg, The Netherlands. - Mémoirs Soc. Roy. Bot. Belgique 11: 115-121.

Willems, J. H. and Lahtinen, M. L. 1997. Impact of pollination and resource limitation on seed production in a border population of Spiranthes spiralis (Orchidaceae). - Acta Bot. Neerl. 46: 365-375.
Zimmerman, J. K. 1990. Role of pseudobulbs in growth and flowering of Catasetum viridiflavum (Orchidaceae). - Am. J. Bot. 77: 533-542.

Zimmerman, J. K. and Whigham, D. F. 1992. Ecological functions of carbohydrates stored in corms of Tipularia discolor (Orchidaceae). - Funct. Ecol. 6: 575-581. 